\title{
Late protein synthesis-dependent phases in CTA long-term memory: BDNF requirement
}

\section{Araceli Martínez-Moreno, Luis F. Rodríguez-Durán and Martha L. Escobar*}

Laboratorio de Neurobiología del Aprendizaje y la Memoria, División de Investigación y Estudios de Posgrado, Facultad de Psicología, Universidad Nacional Autónoma de México, México D.F., México

\section{Edited by:}

Antonella Gasbarri, University of

I'Aquila, Italy

Reviewed by:

Antonella Gasbarri, University of I'Aquila, Italy

Federico Bermudez-Rattoni,

Universidad Nacional Autónoma de

México, Mexico

*Correspondence:

Martha L. Escobar, Laboratorio de Neurobiología del Aprendizaje y la Memoria, División de Investigación y Estudios de Posgrado, Facultad de Psicología, Universidad Nacional Autónoma de México, México D.F. México.

e-mail:mescobar@servidor.unam.mx
It has been proposed that long-term memory (LTM) persistence requires a late protein synthesis-dependent phase, even many hours after memory acquisition. Brain-derived neurotrophic factor (BDNF) is an essential protein synthesis product that has emerged as one of the most potent molecular mediators for long-term synaptic plasticity. Studies in the rat hippocampus have been shown that BDNF is capable to rescue the late-phase of long-term potentiation as well as the hippocampus-related LTM when protein synthesis was inhibited. Our previous studies on the insular cortex (IC), a region of the temporal cortex implicated in the acquisition and storage of conditioned taste aversion (CTA), have demonstrated that intracortical delivery of BDNF reverses the deficit in CTA memory caused by the inhibition of IC protein synthesis due to anisomycin administration during early acquisition. In this work, we first analyze whether CTA memory storage is protein synthesis-dependent in different time windows. We observed that CTA memory become sensible to protein synthesis inhibition 5 and $7 \mathrm{~h}$ after acquisition. Then, we explore the effect of BDNF delivery $(2 \mu \mathrm{g} / 2 \mu \mathrm{l}$ per side) in the IC during those late protein synthesis-dependent phases. Our results show that BDNF reverses the CTA memory deficit produced by protein synthesis inhibition in both phases. These findings support the notion that recurrent rounds of consolidation-like events take place in the neocortex for maintenance of CTA memory trace and that BDNF is an essential component of these processes.

Keywords: BDNF, memory persistence, protein synthesis, CTA, insular cortex

\section{INTRODUCTION}

Is now considered that memory can be divided into at least two stages: a protein synthesis-independent phase (short-term memory; STM), lasting minutes to hours and a protein synthesisdependent phase (long-term memory; LTM), lasting several hours, days, or longer (Bailey et al., 2004; Medina et al., 2008). The process of developing stable memory is referred as consolidation. However, a single molecular cascade consisting of receptor activation, changes in protein phosphorylation, and a transient change in protein production, may be insufficient for the persistence of LTM (Wittenberg and Tsien, 2002; Tsien, 2006). Instead, it has been demonstrated the existence of a delayed protein synthesisdependent phase for behavioral memory persistence, even several hours after memory acquisition (Grecksch and Matthies, 1980; Freeman et al., 1995; Quevedo et al., 1999; Igaz et al., 2002; Bekinschtein et al., 2007; Romero-Granados et al., 2010), showing that specific rounds of consolidation-like events take place for the maintenance of the memory trace.

Brain-derived neurotrophic factor (BDNF) has been considered as a protein synthesis product essential for the expression and persistence of long-term synaptic plasticity in the adult brain (Pang et al., 2004; Bekinschtein et al., 2008a,b; Moguel-Gonzalez et al., 2008). Alonso et al. (2002) showed that hippocampal BDNF is required for the formation of both short- and LTM and is continuously activated, in a time-dependent manner after consolidation for persistence of long-term hippocampal memory (Alonso et al., 2002). Previous studies in the rat hippocampus have demonstrated that application of BDNF is sufficient to rescue the late-phase of long-term potentiation (LTP) after protein synthesis inhibition (Pang et al., 2004). Recently, it has been demonstrated that $12 \mathrm{~h}$ after acquisition of a one-trial associative learning task, there is a novel protein synthesis and BDNF-dependent phase in the rat hippocampus that is critical for the persistence of LTM storage (Bekinschtein et al., 2007, 2008b). BDNF and its high affinity receptor tyrosine kinase receptor B (TrkB) are also abundantly expressed in the neocortex (Yan et al., 1997).

The insular cortex (IC) is a region of the temporal cortex in the rat that has been implicated in the acquisition and storage of different aversive motivated learning tasks like conditioned taste aversion (CTA). CTA is a very robust and widely used model for the study of learning and memory processes in which an animal acquires aversion to a novel taste when it is followed by digestive malaise (Bermudez-Rattoni, 2004; Bernstein and Koh, 2007; Bertrand et al., 2009). Our previous studies demonstrated that acute microinfusion of BDNF in anesthetized adult rats $24 \mathrm{~h}$ before CTA training enhances the retention of this task (Castillo et al., 2006). Moreover, it has been observed that protein translation inhibition impairs CTA consolidation but not acquisition (Rosenblum et al., 1993; Serova et al., 1996; Berman and Dudai, 2001; Moguel-Gonzalez et al., 2008) and we recently reported that acute 
intracortical delivery of BDNF reverses the deficit in CTA memory, caused by inhibition of IC protein synthesis due to anisomycin administration (Moguel-Gonzalez et al., 2008). These evidences suggest that BDNF is an essential protein synthesis product for the establishment of the CTA-LTM. However, the requirement of protein synthesis and BDNF in different time windows after the acquisition of CTA has not been explored so far.

In the present study, we explore the protein synthesisdependence of CTA-LTM in different time windows after acquisition. Then, we analyze the effect of BDNF delivery in the IC during those late protein synthesis-dependent phases.

\section{MATERIALS AND METHODS ANIMALS}

A total of 104 male Wistar rats weighing 345-380 g were prepared for this experiment. Methods were carried out using adequate measures to minimize pain or discomfort, as outlined in the NIH Guide for the Care and Use of Laboratory Animals. They were housed individually under 12/12-h light-dark cycle, with food and water ad libitum (except where indicated) and an average room temperature of $22^{\circ} \mathrm{C}$.

\section{CANNULAE IMPLANTATION}

Animals were implanted bilaterally with 23-gage stainless steel cannulae under anesthesia (Pentobarbital, $50 \mathrm{ml} / \mathrm{kg}$ i.p.) using a previously described procedure (Moguel-Gonzalez et al., 2008). The tips of the guide cannulae were aimed to $2 \mathrm{~mm}$ above the IC (Castillo et al., 2006). Microinjections were delivered through 30gage dental needles as microinjectors that extended $2 \mathrm{~mm}$ below the previously implanted guide cannulae (reaching the IC area). Dental needle microinjectors were attached by polyethylene tubing to a $10-\mu l$ Hamilton syringe driven by a microinfusion pump (Cole Parmer Co.). After surgery animals were allowed to recover for 7 days. All groups were histologically analyzed in order to verify the injector tip location.

\section{CTA TRAINING}

After a 1-week recovery period, animals were introduced in the CTA training, as previously described (Moguel-Gonzalez et al., 2008; Rodriguez-Duran et al., 2011). Briefly, rats were deprived of water for $24 \mathrm{~h}$ and then habituated to drink water from a single graduated cylinder twice a day, during $10 \mathrm{~min}$ trials for 3 days. On the acquisition day, water was substituted for saccharin solution $0.1 \%$ (Sigma, St. Louis, MO, USA), and $10 \mathrm{~min}$ later, the animals received $7.5 \mathrm{ml} / \mathrm{kg}$ i.p. of a $0.15-\mathrm{M}$ solution of $\mathrm{LiCl}$, which induces digestive malaise. After three more days of baseline consumption, water was substituted newly by a $0.1 \%$ saccharin solution to test the aversion. The reduction of saccharin consumption with respect to baseline intake was used as a measure of strength of aversion.

\section{EXPERIMENTAL DESIGN}

It has been demonstrated that protein synthesis inhibition in the IC prevents CTA consolidation (Rosenblum et al., 1993; Berman and Dudai, 2001; Moguel-Gonzalez et al., 2008; Rodriguez-Duran et al., 2011). In order to explore the protein synthesis-dependence of CTA-LTM in different time windows after the acquisition session, intracortical microinfusions of anisomycin at a concentration that has been shown to act for 90 min with a $90 \%$ of protein synthesis inhibition $(100 \mu \mathrm{g} / \mu \mathrm{l}$ per side, Sigma, St. Louis, MO, USA; Rosenblum et al., 1993; Moguel-Gonzalez et al., 2008) were applied at 3 (Ani3, $n=10$ ), 5 (Ani5, $n=8), 7$ (Ani7, $n=10)$, and 12 (Ani12, $n=8$ ) hours after CTA acquisition in the IC (Figure 1B).

It has been observed that BDNF reverses the deficit in CTA memory caused by inhibition of IC protein synthesis due to anisomycin administration (Moguel-Gonzalez et al., 2008). In order to analyze if BDNF delivery is capable of revert the deficit in CTA memory during those time windows in which memory is sensitive to protein synthesis inhibition, intracortical microinfusions of BDNF $(2 \mu \mathrm{g} / 2 \mu \mathrm{l}$ per side, Alomone Labs, Jerusalem; Escobar et al., 2003; Castillo et al., 2006; Moguel-Gonzalez et al., 2008) were applied in the IC immediately after the anisomycin administration at 5 (AniBDNF5, $n=8$ ) or 7 (AniBDNF7, $n=9$ ) hours after CTA acquisition. In a similar manner, intracortical microinfusions of phosphate buffer solution (PBS) were applied immediately after the anisomycin administration at 5 (AniPBS5, $n=10$ ) or 7 (AniPBS7, $n=9$ ) hours after CTA acquisition, as BDNF vehicle. Artificial cerebrospinal fluid (ACSF, $1 \mu \mathrm{l} / \mathrm{min}$ ) microinfusions were applied at 5 (ACSF5, $n=12$ ) or 7 (ACSF7, $n=10$ ) hours after CTA acquisition, as anisomycin vehicle. An additional group (CON, $n=10$ ) was trained in CTA without any pharmacological treatment (Figure 1C). Upon completing the behavioral experiments, cannulated animals were histologically analyzed in order to verify the injector tip location.

\section{RESULTS}

\section{HISTOLOGY}

Histological examinations revealed that injectors were placed in the IC in all the groups (Figure 1A). Two animals with unclear cannulae placements were discarded; one of them was from the AniPBS7 group and the other from the CON group.

\section{CTA BASELINE WATER CONSUMPTION}

No significant differences were found among groups neither in the baseline water intake nor during the first presentation of the conditioned stimulus. The average baseline means ( \pm SEM) of water intake were (in $\mathrm{ml}$ ): $13.56 \pm 0.050,13.33 \pm 0.31,13.78 \pm 0.49$, $13 . \pm 0.60,13.33 \pm 0.46,14.49 \pm 0.60,15.36 \pm 0.34,11.68 \pm 0.72$, $15.77 \pm 0.39,15.20 \pm 0.51$, and $15.98 \pm 0.58$ for the Ani3, Ani5, Ani7, Ani12, AniBDNF5, AniPBS5, ACSF5, AniBDNF7, AniPBS7, ACSF7, and CON groups, respectively.

\section{CTA-LTM IS SENSITIVE TO PROTEIN SYNTHESIS INHIBITION AT 5 AND 7 H AFTER THE ACQUISITION OF THIS TASK}

As shown in Figure 2, intracortical anisomycin microinfusions prevent the persistence of CTA memory when administered 5 and 7 , but not 3 or $12 \mathrm{~h}$ after the acquisition session. ANOVA analysis for saccharin consumption during the aversion test revealed significant differences among groups $\left(F_{4,41}=88.63, p<0.001\right)$. Post hoc analysis with Fisher's test showed that the Ani5 and Ani7 groups had a significant impairment in CTA memory when compared with Ani3, Ani12, and CON groups. The mean of saccharin consumption during the acquisition session for the Ani3, Ani5, Ani7, Ani12, and CON groups were 13.56 \pm 1.05 , $11.62 \pm 3.00,12.8 \pm 1.87,11.62 \pm 1.63$, and $15.46 \pm 2.65$, respectively. These results reveal that CTA-LTM becomes dependent on protein synthesis 5 and $7 \mathrm{~h}$ after memory acquisition. 


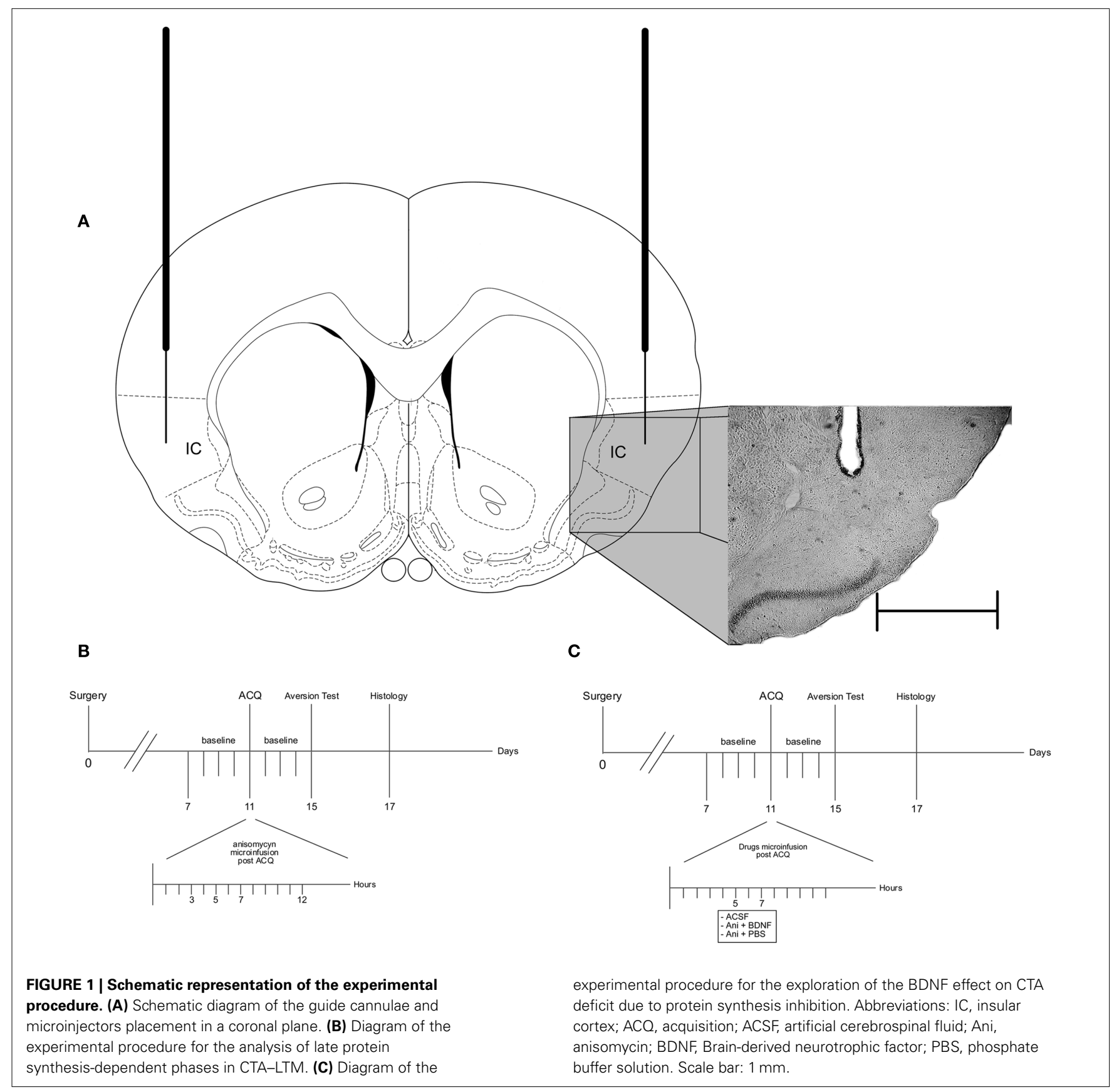

BDNF REVERSES THE DEFICIT IN CTA-LTM CAUSED BY PROTEIN SYNTHESIS INHIBITION AT 5 AND 7 H AFTER THE ACOUISITION OF THIS TASK

Our results show that intracortical delivery of BDNF in the IC reverses the deficit in CTA memory caused by the inhibition of IC protein synthesis at 5 and $7 \mathrm{~h}$ after the acquisition of this task (Figure 3). ANOVA analysis for saccharin consumption during the aversion test revealed significant differences among those groups that were infused $5 \mathrm{~h}\left(F_{3,36}=87.39, p<0.001\right.$; Figure 3$)$ as well as those groups that were infused $7 \mathrm{~h}$ after the acquisition session $\left(F_{3,34}=102.09, p<0.001\right.$, Figure 3). Post hoc analysis with Fisher's test showed that AniBDNF5 and AniBDNF7 groups had a significant improvement in CTA memory persistence as indicated by the decrease of saccharin consumption when compared with the AniPBS5 and AniPBS7 groups. No significant differences were observed among the AniBDNF5, AniBDNF7, ACSF5, ACSF7, and CON groups. The mean of saccharin consumption during the acquisition session for the AniBDNF5, AniPBS5, ACSF5, AniBDNF7, AniPBS7, and ACSF7 groups were $11.55 \pm 1.33,13.00 \pm 1.49,13.83 \pm 1.27,10.88 \pm 1.83$, $14.22 \pm 1.39$, and $15.20 \pm 1.62$, respectively. These results demonstrate that intracortical delivery of BDNF reverses the deficit in CTA memory maintenance caused by inhibition of IC protein synthesis even 5 and $7 \mathrm{~h}$ after memory acquisition. 

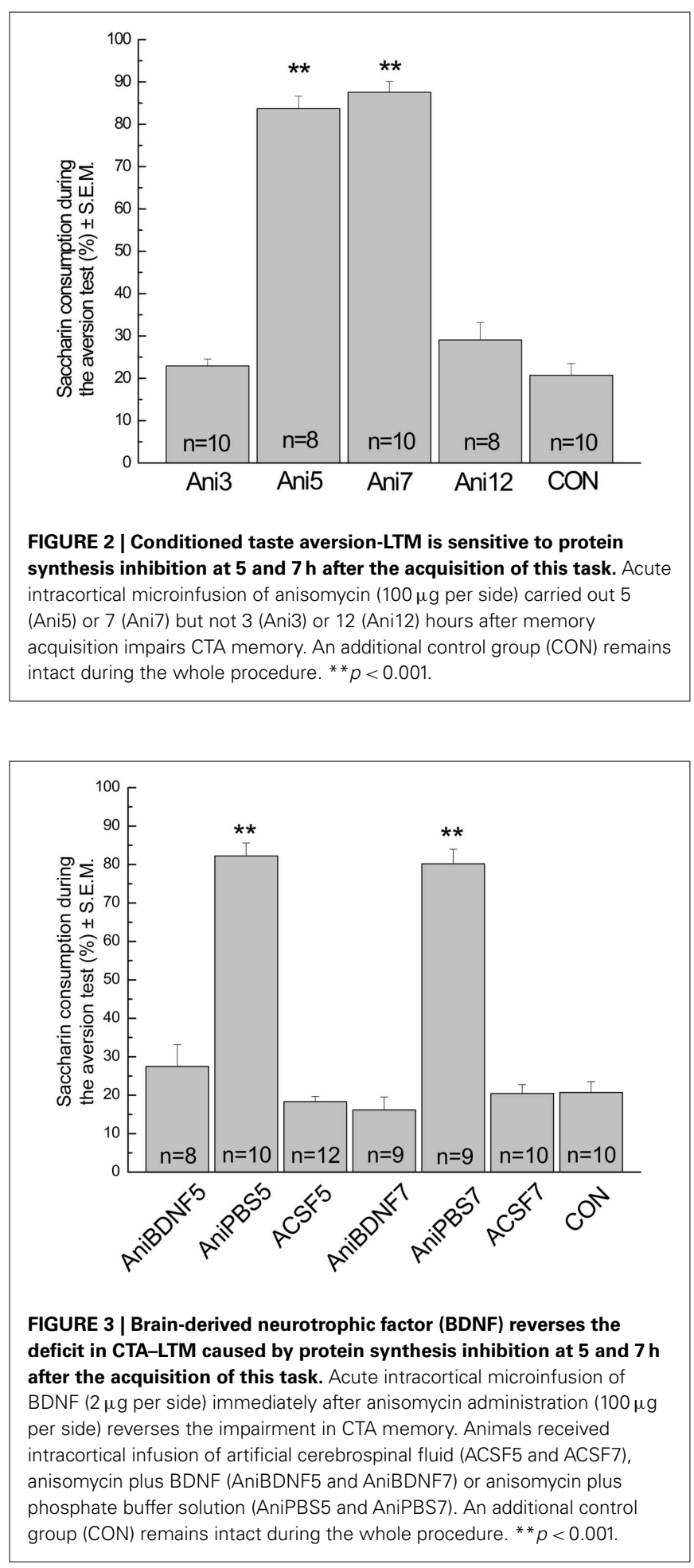

\section{DISCUSSION}

A great body of evidence shows that LTM trace is sensitive to protein synthesis inhibition during the first hours after memory acquisition (McGaugh, 1966, 2000; Davis and Squire, 1984; Kandel, 2001; Barrientos et al., 2002; Dudai, 2002). However, it has been proposed that a single molecular cascade triggered during learning might not be sufficient to account for the persistence of memory in the mammalian brain (Wittenberg and Tsien, 2002), raising the notion that recurrent rounds of consolidation-like events are required for the persistence of LTM in the hippocampus (Bekinschtein et al., 2007). Several studies have been demonstrated that protein synthesis is also critical for memory persistence at least in two time periods: around the time of and several hours after training (Quevedo et al., 1999; Igaz et al., 2002; Bekinschtein et al., 2008b; Romero-Granados et al., 2010). These late protein synthesis-dependent periods have been reported in the rat hippocampus $4 \mathrm{~h}$ after recognition memory formation (RomeroGranados et al., 2010) as well as $12 \mathrm{~h}$ after acquisition of a one-trial IA task (Bekinschtein et al., 2007, 2008b).

The present results show that the persistence of the CTA memory requires a late protein synthesis-dependent phase 5 and $7 \mathrm{~h}$ but not 3 or $12 \mathrm{~h}$ after memory acquisition in the IC, a neocortical area where certain forms of aversive memory are likely to reside (Bermudez-Rattoni, 2004; Moguel-Gonzalez et al., 2008). These results suggest that the reactivation of a cascade of molecular and cellular events takes place in the IC for the maintenance of CTA memory trace.

Brain-derived neurotrophic factor is now considered as an essential protein synthesis product for the establishment of synaptic plasticity (Minichiello, 2009; Bekinschtein et al., 2010; Musumeci and Minichiello, 2011). Our previous studies show that acute intrahippocampal microinfusion of BDNF induces LTP in the hippocampal DG-CA3 (mossy fiber) projection. This potentiation was accompanied by a presynaptic structural long-lasting reorganization and a change in the possibility to induce subsequent LTP at the mossy fiber pathway (Gomez-Palacio-Schjetnan and Escobar, 2008; Schjetnan and Escobar, 2010). In addition, it has been shown that BDNF induces long-term modifications that underlie the late-phase of LTP in the CA1 area of the hippocampus (Pang et al., 2004). Moreover, intrahippocampal microinfusion of BDNF induces memory persistence by itself transforming a nonlasting LTM trace into a persistent one (Bekinschtein et al., 2008b). In the other hand, our studies in the IC have shown that exogenous application of BDNF in the IC enhances synaptic efficacy in the basolateral amygdaloid nucleus-IC projection and modifies the retention of CTA (Escobar et al., 2003; Castillo et al., 2006; Castillo and Escobar, 2011) and recently we showed that the deficit in CTA memory caused by the inhibition of protein synthesis in the IC, during the acquisition session is reversed by an acute intracortical delivery of BDNF (Moguel-Gonzalez et al., 2008).

In the present work we show that acute intracortical delivery of BDNF reverses the deficit in CTA memory caused by the inhibition of IC protein synthesis due to anisomycin administration 5 and $7 \mathrm{~h}$ after memory acquisition. BDNF is essential for the consolidation of CTA memory early after acquisition (Moguel-Gonzalez et al., 2008) and the present data reveals that this neurotrophin is also required for CTA-LTM persistence even several hours after the acquisition session.

In the same order of ideas, it has been demonstrated that BDNF endogenous expression is modulated in different time windows during the formation of LTM (Ou et al., 2010; Ma et al., 2011). In a recent study Ou et al. (2010) showed that fear conditioning 
training triggers two peaks of BDNF expression in the amygdala, at 1 and $12 \mathrm{~h}$ after conditioning. In the hippocampus, IA memory presents a BDNF-dependent phase $12 \mathrm{~h}$ after training and BDNF infusion into this time window transform a non-lasting LTM trace into a persistent one (Bekinschtein et al., 2008b). These evidences suggest that an endogenous increase in BDNF production is necessary for the maintenance of LTM. In a similar manner, a recent study of Ma et al. (2011) shows the specific regional involvement of BDNF secretion and synthesis in the CTA-LTM. They reported that the CTA training induces an increase in BDNF levels at the IC. This increase starts at $2 \mathrm{~h}$, peaked at 6 and returned to baseline at $8 \mathrm{~h}$ after CTA acquisition (Ma et al., 2011). Accordingly, in the present work, we observed that intracortical delivery of BDNF is sufficient to reverse the LTM impairment produced by anisomycin microinfusion, within the time of BDNF expression presented by Ma et al., 2011; 5 and $7 \mathrm{~h}$ after the CTA acquisition), suggesting that a late-phase of endogenous release of BDNF is required for the maintenance of CTA-LTM.

Release of BDNF initiates a cascade of molecular mechanisms related with activity-dependent synaptic changes (Minichiello, 2009; Musumeci and Minichiello, 2011). This neurotrophin and its high affinity receptor TrkB trigger a molecular cascade of proteins, as the mitogen-activated protein kinase (MAPK), the phospholipase C-gamma (PLC-gamma) and the phosphatidylinositol-3 kinase (PI-3K) pathways (Minichiello et al., 2002). Through these pathways, BDNF regulates the activity-dependent changes in synaptic properties related with the maintenance of the LTM of several learning tasks (Yamada and Nabeshima, 2003). For example, training in the IA task requires a late BDNF-dependent phase in the hippocampus $12 \mathrm{~h}$ after training (Bekinschtein et al., 2007). In addition, it has been observed a late increase in extracellular signal-regulated kinases (ERK) phosphorylation levels in the hippocampus $12 \mathrm{~h}$ after IA training, and intrahippocampal infusion of the MAPK kinase (MEK) inhibitor, U0126, resulted in a deficit in LTM retention (Bekinschtein et al., 2008b). Our previous studies on the IC showed that microinfusion of BDNF previous to CTA training modifies the retention of this task, through

\section{REFERENCES}

Alonso, M., Vianna, M. R., Depino, A. M., Mello E Souza, T., Pereira, P., Szapiro, G., Viola, H., Pitossi, F., Izquierdo, I., and Medina, J. H. (2002). BDNF-triggered events in the rat hippocampus are required for both short- and long-term memory formation. Hippocampus 12, 551-560.

Bailey, C. H., Kandel, E. R., and Si, K. (2004). The persistence of long-term memory: a molecular approach to self-sustaining changes in learninginduced synaptic growth. Neuron 44 , 49-57.

Barrientos, R. M., O’Reilly, R. C., and Rudy, J. W. (2002). Memory for context is impaired by injecting anisomycin into dorsal hippocampus following context exploration. Behav. Brain Res. 134, 299-306.
Bekinschtein, P., Cammarota, M., Igaz, L. M., Bevilaqua, L. R., Izquierdo, I., and Medina, J. H. (2007). Persistence of long-term memory storage requires a late protein synthesisand BDNF- dependent phase in the hippocampus. Neuron 53, 261-277.

Bekinschtein, P., Cammarota, M., Izquierdo, I., and Medina, J. H. (2008a). BDNF and memory formation and storage. Neuroscientist 14, 147-156.

Bekinschtein, P., Cammarota, M., Katche, C., Slipczuk, L., Rossato, J. I., Goldin, A., Izquierdo, I., and Medina, J. H. (2008b). BDNF is essential to promote persistence of long-term memory storage. Proc. Natl. Acad. Sci. U.S.A. 105, 2711-2716.

Bekinschtein, P., Katche, C., Slipczuk, L., Gonzalez, C., Dorman,

the activation of MAPK and PI-3K at the IC (Castillo et al., 2006; Castillo and Escobar, 2011). The mentioned molecular cascades converge in the activation of transcription factors, such as cyclic adenosine monophosphate response element-binding protein (CREB), which induce gene expression (e.g., Arc and Zif 286) and thereby LTM-related synaptic changes (Minichiello et al., 2002; Minichiello, 2009).

Although the molecular mechanisms triggered by BDNF underlying the persistence of behavioral memories remains unclear, it has been observed that BDNF enhances the expression of the protein kinase $\mathrm{M} \zeta(\mathrm{PKM} \zeta)$, an atypical isoform of the protein kinases $\mathrm{C}(\mathrm{PKC})$ which plays a crucial role in the persistence of LTM in several behavioral tasks, including CTA (Shema et al., 2007, 2009, 2011; Gamiz and Gallo, 2011; Sacktor, 2011). The local synthesis of BDNF and PKM $\zeta$ are required for the maintenance of certain forms of LTP (Sajikumar and Korte, 2011) and recently, Mei et al. (2011) demonstrated that BDNF is capable to sustain the late-phase of LTP through PKM $\zeta$ in a protein synthesisindependent manner, providing a strong mechanistic link between $\mathrm{BDNF}$ and $\mathrm{PKM} \zeta$ in the persistence of synaptic plasticity.

In summary, the present results show that CTA memory becomes sensible to protein synthesis inhibition 5 and $7 \mathrm{~h}$ after memory acquisition, revealing that new protein synthesis is required for the maintenance of CTA-LTM even hours after acquisition. Furthermore, BDNF reverses the CTA memory deficit produced by protein synthesis inhibition during both late-phases, showing that BDNF is an essential protein product for the persistence of CTA in different post-acquisition time windows. These evidences suggest that a new round of consolidation-like events take place in the IC for the maintenance of the CTA memory trace and stress the role of BDNF as a key protein which promotes the persistence of LTM in the neocortex.

\section{ACKNOWLEDGMENTS}

This research was supported by PAPIIT IN213210 and CONACYT 60851. We acknowledge Andrea Gómez-Palacio-Schjetnan for comments on the manuscript.

G., Cammarota, M., Izquierdo, I., and Medina, J. H. (2010). Persistence of long-term memory storage: new insights into its molecular signatures in the hippocampus and related structures. Neurotox. Res. 18, 377-385.

Berman, D. E., and Dudai, Y. (2001). Memory extinction, learning anew, and learning the new: dissociations in the molecular machinery of learning in cortex. Science 291, 2417-2419.

Bermudez-Rattoni, F. (2004). Molecular mechanisms of taste-recognition memory. Nat. Rev. Neurosci. 5, 209-217.

Bernstein, I. L., and Koh, M. T. (2007). Molecular signaling during taste aversion learning. Chem. Senses 32, 99-103.
Bertrand, D., Yannick, S., Mathilde, B. Frederic, L., Nadine, R., and Guillaume, F. (2009). Critical role of insular cortex in taste but not odour aversion memory. Eur. J. Neurosci. 29, 1654-1662.

Castillo, D. V., and Escobar, M. L. (2011). A role for MAPK and PI-3K signaling pathways in brain-derived neurotrophic factor modification of conditioned taste aversion retention. Behav. Brain Res. 217, 248-252.

Castillo, D. V., Figueroa-Guzman, Y., and Escobar, M. L. (2006). Brain-derived neurotrophic factor enhances conditioned taste aversion retention. Brain Res. 1067, 250-255.

Davis, H. P., and Squire, L. R. (1984). Protein synthesis and memory: a review. Psychol. Bull. 96, 518-559. 
Dudai, Y. (2002). Molecular bases of long-term memories: a question of persistence. Curr. Opin. Neurobiol. 12, 211-216.

Escobar, M. L., Figueroa-Guzman, Y., and Gomez-Palacio-Schjetnan, A. (2003). In vivo insular cortex LTP induced by brain-derived neurotrophic factor. Brain Res. 991, 274-279.

Freeman, F. M., Rose, S. P., and Scholey, A. B. (1995). Two time windows of anisomycin-induced amnesia for passive avoidance training in the day-old chick. Neurobiol. Learn. Mem. 63, 291-295.

Gamiz, F., and Gallo, M. (2011). Intraamygdala ZIP injections impair the memory of learned active avoidance responses and attenuate conditioned taste-aversion acquisition in rats. Learn. Mem. 18, 529-533.

Gomez-Palacio-Schjetnan, A., and Escobar, M. L. (2008). In vivo BDNF modulation of adult functional and morphological synaptic plasticity at hippocampal mossy fibers. Neurosci. Lett. 445, 62-67.

Grecksch, G., and Matthies, H. (1980). Two sensitive periods for the amnesic effect of anisomycin. Pharmacol. Biochem. Behav. 12, 663-665.

Igaz, L. M., Vianna, M. R., Medina, J. H., and Izquierdo, I. (2002). Two time periods of hippocampal mRNA synthesis are required for memory consolidation of fear-motivated learning. J. Neurosci. 22, 6781-6789.

Kandel, E. R. (2001). The molecular biology of memory storage: a dialogue between genes and synapses. Science 294, 1030-1038.

Ma, L., Wang, D. D., Zhang, T. Y., Yu, H., Wang, Y., Huang, S. H., Lee, F. S., and Chen, Z. Y. (2011). Region-specific involvement of BDNF secretion and synthesis in conditioned taste aversion memory formation. J. Neurosci. 31, 2079-2090.

McGaugh, J. L. (1966). Time-dependent processes in memory storage. Science 153, 1351-1358.

McGaugh, J. L. (2000). Memory-a century of consolidation. Science 287, 248-251.
Medina, J. H., Bekinschtein, P., Cammarota, M., and Izquierdo, I. (2008). Do memories consolidate to persist or do they persist to consolidate? Behav. Brain Res. 192, 61-69.

Mei, F., Nagappan, G., Ke, Y., Sacktor, T. C., and Lu, B. (2011). BDNF facilitates L-LTP maintenance in the absence of protein synthesis through PKMzeta. PLoS ONE 6, e21568. doi: 10.1371/journal.pone.0021568

Minichiello, L. (2009). TrkB signalling pathways in LTP and learning. Nat. Rev. Neurosci. 10, 850-860.

Minichiello, L., Calella, A. M., Medina, D. L., Bonhoeffer, T., Klein, R., and Korte, M. (2002). Mechanism of TrkB-mediated hippocampal long-term potentiation. Neuron 36, 121-137.

Moguel-Gonzalez, M., Gomez-PalacioSchjetnan, A., and Escobar, M. L. (2008). BDNF reverses the CTA memory deficits produced by inhibition of protein synthesis. Neurobiol. Learn. Mem. 90, 584-587.

Musumeci, G., and Minichiello, L. (2011). BDNF-TrkB signalling in fear learning: from genetics to neural networks. Rev. Neurosci. 22, 303-315.

Ou, L. C., Yeh, S. H., and Gean, P. W. (2010). Late expression of brainderived neurotrophic factor in the amygdala is required for persistence of fear memory. Neurobiol. Learn. Mem. 93, 372-382.

Pang, P. T., Teng, H. K., Zaitsev, E., Woo, N. T., Sakata, K., Zhen, S., Teng, K. K., Yung, W. H., Hempstead, B. L., and Lu, B. (2004). Cleavage of proBDNF by tPA/plasmin is essential for longterm hippocampal plasticity. Science 306, 487-491.

Quevedo, J., Vianna, M. R., Roesler, R., De-Paris, F., Izquierdo, I., and Rose, S. P. (1999). Two time windows of anisomycin-induced amnesia for inhibitory avoidance training in rats: protection from amnesia by pretraining but not pre-exposure to the task apparatus. Learn. Mem. 6, 600-607.

Rodriguez-Duran, L. F., Castillo, D. V., Moguel-Gonzalez, M., and Escobar,
M. L. (2011). Conditioned taste aversion modifies persistently the subsequent induction of neocortical long-term potentiation in vivo. Neurobiol. Learn. Mem. 95, 519-526.

Romero-Granados, R., Fontan-Lozano, A., Delgado-Garcia, J. M., and Carrion, A. M. (2010). From learning to forgetting: behavioral, circuitry, and molecular properties define the different functional states of the recognition memory trace. Hippocampus 20, 584-595.

Rosenblum, K., Meiri, N., and Dudai, Y. (1993). Taste memory: the role of protein synthesis in gustatory cortex. Behav. Neural Biol. 59, 49-56.

Sacktor, T. C. (2011). How does PKMzeta maintain long-term memory? Nat. Rev. Neurosci. 12, 9-15.

Sajikumar, S., and Korte, M. (2011). Metaplasticity governs compartmentalization of synaptic tagging and capture through brain-derived neurotrophic factor (BDNF) and protein kinase Mzeta (PKMzeta). Proc. Natl. Acad. Sci. U.S.A. 108, 2551-2556.

Schjetnan, A. G., and Escobar, M. L. (2010). In vivo BDNF modulation of hippocampal mossy fiber plasticity induced by high frequency stimulation. Hippocampus doi: 10.1002/hipo.20866

Serova, O. N., Solov'ea, N. A., Lagutina, L. V., and Obukhova, M. F. (1996). Formation of taste aversion and preference in protein synthesis inhibition in rats. Neurosci. Behav. Physiol. 26, 477-481.

Shema, R., Haramati, S., Ron, S., Hazvi, S., Chen, A., Sacktor, T. C., and Dudai, Y. (2011). Enhancement of consolidated long-term memory by overexpression of protein kinase Mzeta in the neocortex. Science 331, 1207-1210.

Shema, R., Hazvi, S., Sacktor, T. C., and Dudai, Y. (2009). Boundary conditions for the maintenance of memory by PKMzeta in neocortex. Learn. Mem. 16, 122-128.

Shema, R., Sacktor, T. C., and Dudai, Y. (2007). Rapid erasure of long-term memory associations in the cortex by an inhibitor of PKM zeta. Science 317, 951-953.

Tsien, J. Z. (2006). "Learning and memory," in Basic Neurochemistry: Molecular, Cellular and Medical Aspects, 7th Edn, eds G. J. Siegel, R. W. Albers, S. Brandy, and D. Price (Amsterdam: Elsevier), 859-874.

Wittenberg, G. M., and Tsien, J. Z. (2002). An emerging molecular and cellular framework for memory processing by the hippocampus. Trends Neurosci. 25, 501-505.

Yamada, K., and Nabeshima, T. (2003). Brain-derived neurotrophic factor/TrkB signaling in memory processes. J. Pharmacol. Sci. 91, 267-270.

Yan, Q., Rosenfeld, R. D., Matheson, C. R., Hawkins, N., Lopez, O. T., Bennett, L., and Welcher, A. A. (1997). Expression of brainderived neurotrophic factor protein in the adult rat central nervous system. Neuroscience 78, 431-448.

Conflict of Interest Statement: The authors declare that the research was conducted in the absence of any commercial or financial relationships that could be construed as a potential conflict of interest.

Received: 27 July 2011; paper pending published: 09 August 2011; accepted: 02 September 2011; published online: 22 September 2011.

Citation: Martínez-Moreno A, Rodríguez-Durán LF and Escobar ML (2011) Late protein synthesis-dependent phases in CTA long-term memory: BDNF requirement. Front. Behav. Neurosci. 5:61. doi: 10.3389/fnbeh.2011.00061 Copyright (C) 2011 Martínez-Moreno, Rodríguez-Durán and Escobar. This is an open-access article subject to a nonexclusive license between the authors and Frontiers Media SA, which permits use, distribution and reproduction in other forums, provided the original authors and source are credited and other Frontiers conditions are complied with. 